\title{
Parameters estimation of BLDC motor based on physical approach and weighted recursive least square algorithm
}

\author{
Rania Majdoubi ${ }^{1}$, Lhoussaine Masmoudi², Mohammed Bakhti ${ }^{3}$, \\ Abderrahmane Elharif ${ }^{4}$, Bouazza Jabri ${ }^{5}$ \\ ${ }_{1,2,4,5}$ LCS Laboratory, Faculty of Science, Mohammed V University in Rabat, Morocco \\ ${ }^{3}$ L2MC Laboratory, ENSAM, Moulay Ismail University in Meknes, Morocco
}

\section{Article Info}

Article history:

Received Apr 11, 2020

Revised Jun 20, 2020

Accepted Aug 4, 2020

\section{Keywords:}

Brushless DC motors

Online identification

Parameters identification

Park's reference frame

Physical approach

Weighted recursive least square

\begin{abstract}
Brushless DC motors (BLDCM) are widely used when high precision converters are required. Model based torque control schemes rely on a precise representation of their dynamics, which in turn expect reliable system parameters estimation. In this paper, we propose two procedures for BLDCM parameters identification used in an agriculture mobile robot's wheel. The first one is based on the physical approach or equations using experimentation data to find the electrical and mechanical parameters of the BLDCM. The parameters are then used to elaborate the model of the motor established in Park's reference frame. The second procedure is an online identification based on recursive least square algorithm. The procedure is implemented in a closed-loop scheme to guarantee the stability of the system, and it provide parameter matrices obtained by transforming electrical equations, established in Parks reference frame, and mechanical equation to discrete-time domain. From these matrices, and using well formulated intermediate variables, all desired parameters are deduced simultaneously. The identification procedures are being verified using simulation under Matlab-Simulink software.
\end{abstract}

This is an open access article under the CC BY-SA license.

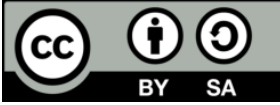

\section{Corresponding Author:}

Rania Majdoubi,

LCS Laboratory, Faculty of Science,

Mohammed V University in Rabat,

4 Ibn Batouta Road, P.O. Box 1014, Rabat, Morocco.

Email: rania_majdoubi@um5.ac.ma

\section{INTRODUCTION}

Systems identification is a major preoccupation in the majority of scientific disciplines. It refers to both a scientific approach and a set of techniques that reproduce as faithfully as possible the behavior of a physical system [1]. Parameter identification is used to obtain an accurate model of a real system, provides an appropriate platform for further design developments and/or the study of its control strategies. Indeed, the control of industrial processes usually requires the use of reliable models that are close to physical reality.

Once the model of a system is set, it is necessary to apply identification methods in order to match, as accurately as possible, the behaviour of the model and that of the targeted system. Identifying a system consists of a description of its behavior based on the experimental data and any apriori available knowledge used to build a mathematical model with identical dynamic behavior [2, 3]. In automatic control, the system identification is one of the fundamental and essential steps prior to system analysis achieved by conducted simulation or control algorithms synthesis. It can be grouped into two main families: Non-parametric identification and parametric identification as described by I. Z. Mat in [4]. The most important problems 
found in mechatronic system is that the characteristics of brushless de motors (BLDCMs) are often not available since the engine manufacturer doesn't communicate additional details about the product. Another problem is that the BLDCMs need to be calibrated during preventive inspection to perform any control operation correctly [5].

In this paper, we focus on parametric identification because the model is based on the physics laws. We, therefore, have a set of physical parameters to be identified, making non-parametric identification useless. Fortunately, the parameter estimation of mechatronic systems has been an important topic in literature, among them the traditional theory which is developed in the papers [6-9]. Many authors use different sensorless techniques [10] to estimate motor parameters. Therefore, the sensorless techniques mentioned in the literature are classified into counter-electromotive force, induction variation, observers and intelligent methods as detailed in $[11,12]$. In particular, various methods have been applied to the brushless DC motor for the identification of motor parameters. Several studies use the algebraic identification method as detailed by G. Mamani and all in papers [13, 14]. Krneta and all in [15], Yehia and all in [16] use the recursive least squares algorithm method. Rijad and all in [17] propose a new approach to linear control systems in closed loop to identify motor parameters. Some methods identify motor parameters by using particular signals or under certain load conditions as detailed in the paper [18], but this technique is hard to be achieved because it is difficult to both; identify the motor parameters under motor control and to respond to changes in these parameters. Other methods are used to online identify motor parameters as detailed in papers [19] and [20], In one method [19], the accuracy of the identified parameters depends on the accuracy of the estimation, because rotor position and speed are used to identify the motor parameters, and Another method [20], the stator resistance and back EMF constant are identified, but the inductances cannot be identified. Andreev and all in [21] propose an algorithm which is based on the analysis of a current tube of electric motor phases to identify motor parameters. Frolov and all in [22] use operational mode to identify motor parameters. Another technique to identify motor parameters is elaborated by Katarzyna in [23] that uses the genetic algorithm.

Based on the methods mentioned above, we form the objective which will be the electrical and mechanical parameter estimation of a BLDC motor to control the torque adapted to the wheels of a mobile agricultural robot in soft soil [24, 25]. Therefore, in this paper two methods have been chosen for the estimation of these parameters on which ones leads to the other: the first one concerns the physical approach through motor equations in continuous-time with the help of experimental data, and the other one is using the weighted recursive least square algorithm through modeling and regulating the BLDC motor to ensure the stability of the system. Hence, this estimation is done in discrete-time of the inverse models established in Parks frame using methods of the input error type minimizing the difference between the actual input and the input estimated by the inverse model. This technique provides also a sensorless estimation of the angular velocity and the torque generated by the motor.

The remaining of this paper is organized as follows: In section 2, we present the Parameter identification methods that include the physical approach method and the online estimation method. Section 3 is about the result of these methods. Hence, in the physical approach, we will identify the electrical and mechanical parameters using experimentation set-up in the case of the motor without taking into account the commutation. Once the physical identification is achieved, the found parameters are applied to the online estimation approach based on the weighted recursive least square algorithm which is validated under MatlabSimulink software. Finally, section 4 concludes the paper and formulate some suggestions for future work.

\section{PARAMETERS IDENTIFICATION METHODS}

\subsection{Physical approach method}

\subsubsection{BLDC Motor modeling}

In the case where commutation is not taken into account, the mathematical modeling of the BLDCM is simplified by the electrical and the mechanical equations. Electrical equation is presented in (1).

$$
\begin{aligned}
& V=R i+L \frac{d i}{d t}+e \\
& \mathrm{e}=p \phi_{m} \omega
\end{aligned}
$$

The mechanical equation is presented in (2).

$$
\begin{aligned}
& C_{e m}-C_{r}=f_{v} \omega+J \frac{d \omega}{d t} \\
& C_{e m}=p \phi_{m} i
\end{aligned}
$$


Where: $\mathrm{V}$ is the motor terminal voltage, $i$ is the winding current, $\mathrm{e}$ is the back-EMF of the motor, $\mathrm{p}$ is the number of pole pairs of the motor, $\mathrm{R}$ is the terminal resistance, $\phi_{m}$ is the maximum flux produced by the rotor in a stator winding, $\mathrm{J}$ is the inertia of the rotor, $C_{e m}$ is the motor torque provided by the stator, $C_{r}$ is the load resistance torque and $f_{v}$ is the viscous friction coefficient. Then, the electrical and mechanical parameters can be estimated experimentally using these equations.

\subsubsection{Estimation of electrical and mechanical parameters}

a) Resistance estimation method

The resistance $\mathrm{R}$ can be directly measured by means of an ohmmeter. The value indicated by this instrument must be adapted to the stator coupling: Triangle $(\Delta)$ or Star $(\mathrm{Y})$. For this reason, the coefficient $a$ must be calculated to determine the type of connection. Hence, we calculate the report as mentioned as follows:

$$
a=\frac{R_{2}}{R_{1}}
$$

where:

$R_{1}$ is the measured resistance between phases,

$R_{2}$ is the resistance measured between two phases and the third one.

If $a=0.75$, the coupling is Star and the resistance $\mathrm{R}$ is $\frac{R_{1}}{2}$

If $a=0.5$, the coupling is Triangle and the resistance $\mathrm{R}$ is $R_{1}$

b) Inductance estimation method

A signal or function generator was used for the estimation. Thus, we applied a known amplitude and frequency voltage between two motor phases and measure the current flowing through the windings using an ampermeter the module of stator impedance $Z$ is expressed in the (4).

$$
\begin{aligned}
& |Z|=\sqrt{R^{2}+(L \omega)^{2}}=\frac{V}{2 i} \\
& \omega=2 \pi f
\end{aligned}
$$

where:

$\mathrm{R}$ is the value of the resistance previously estimated,

$\mathrm{V}$ is the amplitude of the voltage applied between two phases,

$i$ is the current measured while applying the voltage $\mathrm{V}$,

$\omega$ is the pulsation of the voltage applied to the phases of the motor,

$f$ is the frequency of the voltage applied between two phases.

c) Maximum magnetic flux estimation method

According to (1), to estimate the constant $\phi_{m}$, a steady voltage is applied to the motor. Then, the current becomes steady $\left(\frac{d i}{d t}=0\right)$, hence the induction term can be deleted and the (1) becomes:

$$
\frac{V}{i}=p \phi_{m} \frac{\omega}{i}+R
$$

d) Viscous friction coefficient estimation method

At a given current a constant angular velocity is achieved. Then, we get $\frac{d \omega}{d t}=0$. From the (2), we get the (6).

$$
p \phi_{m} i=f_{v} \omega+C_{r}
$$

e) Moment of inertia estimation method

When the motor is powered for a period of time and then cut off, the angular velocity characteristic as a function of time is defined as shown in Figure 1.

And according to the (2), we get the following equation:

$$
f_{v} \omega=-J \frac{d \omega}{d t}+C_{r}
$$


Our measurement cannot be done during transient phase, because the time is very short (impossible for measurement), similar purpose as in the steady state because $\frac{d \omega}{d t}=0$. Hence the measurement is done during the coasting phase while several resistive torques are applied.

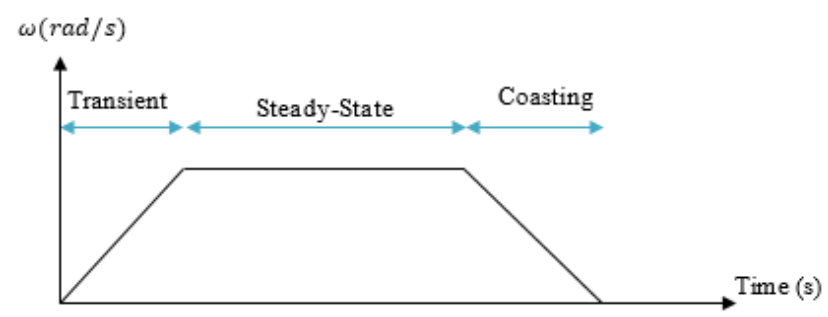

Figure 1. Phases of the $\omega$ characteristic as a function of time

\subsection{Online estimation approach}

\subsubsection{Electrical and mechanical BLDC motor modeling}

The direct model of the BLDC motor was developed using MATLAB Simulink software as described in Figure 2, but their inverse model that will be used in our work is obtained from the motor modeling in the Park's reference frame: Electrical equations and mechanical equation as described in [26-29].

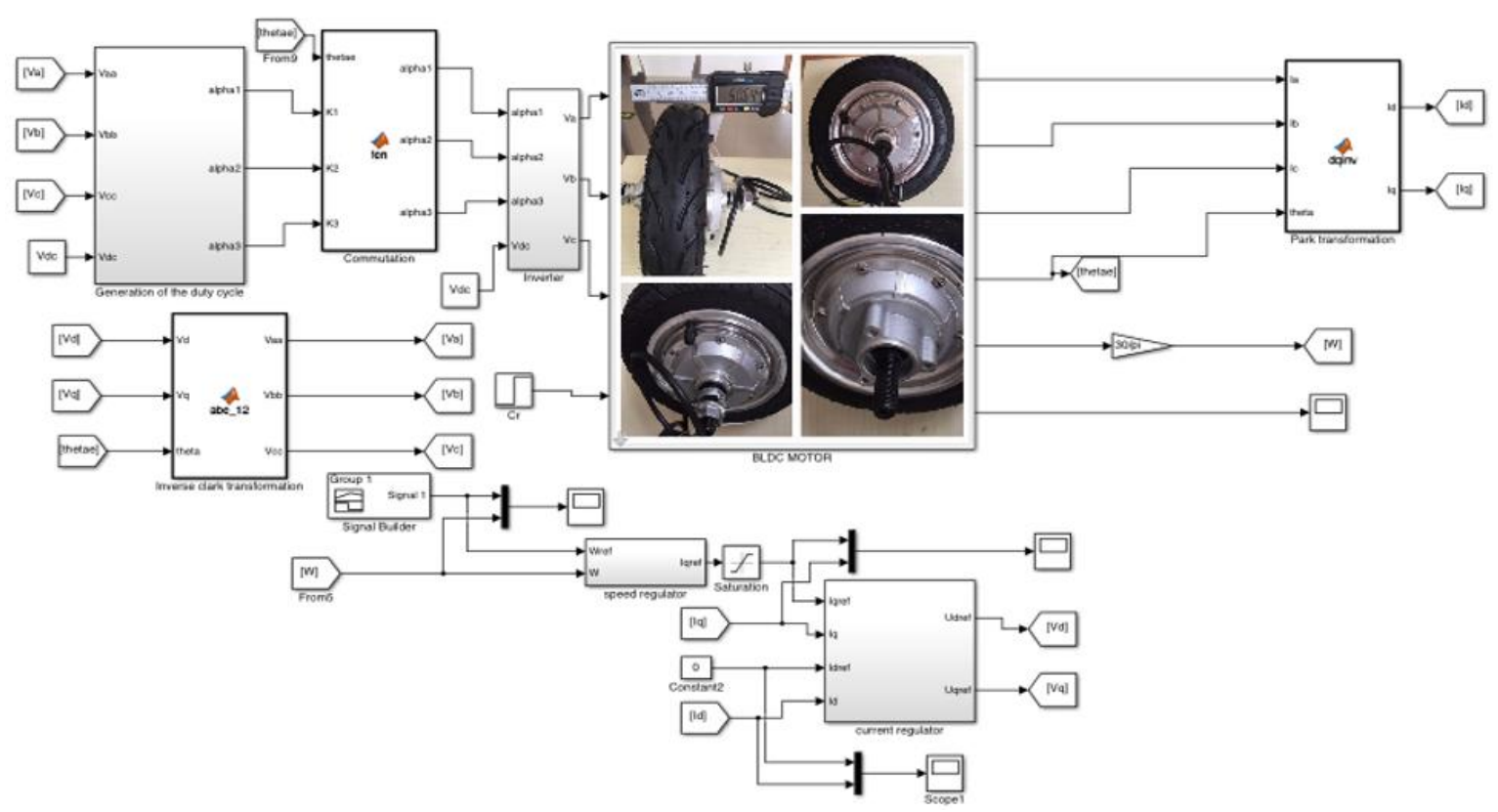

Figure 2. Simulation of BLDC motor with close loop regulation

Two equations will be useful for the identification of the electrical parameters, these equations are presented as follows:

$$
\begin{aligned}
& \frac{d i_{d}}{d t}=\frac{1}{L_{d}}\left(-R i_{d}+V_{d}+p \omega L_{q} i_{q}\right) \\
& \frac{d i_{q}}{d t}=\frac{1}{L_{q}}\left(-R i_{q}+V_{q}-p \omega L_{d} i_{d}+p \omega \Phi_{m}\right)
\end{aligned}
$$

and to identify the mechanical parameters, we use the equation as shown in (10). 


$$
\frac{d \omega}{d t}=\frac{1}{J}\left(C_{e m}-f_{v} \omega\right)
$$

Where: $V_{d}$ and $V_{q}$ are the voltages projected in park's reference frame, $i_{d}$ and $i_{q}$ are the currents projected in park's reference frame, $L_{d}$ and $L_{q}$ are the direct inductance and quadratic inductance.

In our case, we suppose that the motor is without salience, thus:

$$
L_{d}=L_{q}=L
$$

The parameters to be identified are the electrical parameters $\left[\mathrm{R}, L_{d}, L_{q}, \Phi_{m}\right]$ and mechanical parameters $\left[f_{v}, \mathrm{~J}\right]$.

\subsubsection{Electrical and mechanical BLDC motor modelling}

a) Parameter matrix estimation

The estimation method identifies the unknown electrical and mechanical parameters for the motor by means of a mathematical model using known values such as voltages, currents, electromotive torque and angular velocity as shown in (8), (9) and (10). In this case, the weighted recursive least squares method was chosen. By transforming (8), (9) and (10) into discrete time. The state equations become:

$$
\left[\begin{array}{l}
i_{d}(n+1) \\
i_{q}(n+1) \\
\omega(n+1)
\end{array}\right]=A\left[\begin{array}{c}
i_{d}(n) \\
i_{d}(n) \\
\omega(n)
\end{array}\right]+B\left[\begin{array}{c}
V_{d}(n) \\
V_{q}(n) \\
C_{e m}(n)
\end{array}\right]+C f\left(i_{d}(n), i_{q}(n), \omega(n)\right)
$$

where:

$$
\begin{aligned}
& A=\left(\begin{array}{lll}
a_{11} & a_{12} & a_{13} \\
a_{21} & a_{22} & a_{23} \\
a_{31} & a_{32} & a_{33}
\end{array}\right) \quad \text { as } \\
& B=\left(\begin{array}{lll}
b_{11} & b_{12} & b_{13} \\
b_{21} & b_{22} & b_{23} \\
b_{31} & b_{32} & b_{33}
\end{array}\right) \quad \text { as: } \\
& \left\{\begin{array}{c}
\mathrm{b}_{11}=\frac{1}{\mathrm{~L}_{\mathrm{d}}} \Delta \mathrm{T} \\
\mathrm{b}_{22}=\frac{1}{\mathrm{~L}_{\mathrm{q}}} \Delta \mathrm{T} \\
\mathrm{b}_{33}=\frac{1}{\mathrm{~J}} \Delta \mathrm{T} \\
\mathrm{b}_{12}=\mathrm{b}_{13}=\mathrm{b}_{21}=\mathrm{b}_{23}=\mathrm{b}_{31}=\mathrm{b}_{32}=0
\end{array},\right. \\
& \mathbf{C}=\left(\begin{array}{lll}
\mathbf{c}_{11} & \mathbf{c}_{12} & \mathbf{c}_{13} \\
\mathbf{c}_{21} & \mathbf{c}_{22} & \mathbf{c}_{23} \\
\mathbf{c}_{31} & \mathbf{c}_{32} & \mathbf{c}_{33}
\end{array}\right) \quad \text { as: } \\
& \left\{\begin{array}{c}
\mathrm{c}_{11}=\frac{\mathrm{pL}_{\mathrm{q}}}{\mathrm{L}_{\mathrm{d}}} \Delta \mathrm{T} \\
\mathrm{c}_{22}=-\frac{\mathrm{pL}_{\mathrm{d}}}{\mathrm{L}_{\mathrm{q}}} \Delta \mathrm{T} \\
\mathrm{c}_{12}=\mathrm{c}_{13}=\mathrm{c}_{21}=\mathrm{c}_{23}=\mathrm{c}_{31}=\mathrm{c}_{32}=\mathrm{c}_{33}=0
\end{array},\right. \\
& f\left(i_{d}(n), i_{q}(n), \omega(n)\right)=\left(\begin{array}{c}
i_{q}(n) \omega(n) \\
i_{d}(n) \omega(n) \\
\omega(n)^{2}
\end{array}\right)
\end{aligned}
$$

The (11) is transformed as follows:

$$
Y_{p}=P_{p} Z_{p}
$$

where:

$$
\begin{aligned}
& Y_{p}=\left[\begin{array}{lll}
i_{d}(n+1) & i_{q}(n+1) & \omega(n+1)
\end{array}\right]^{T} \\
& \mathrm{Z}_{\mathrm{p}}=\left[\begin{array}{lll}
\mathrm{i}_{\mathrm{d}}(\mathrm{n}) \mathrm{i}_{\mathrm{q}}(\mathrm{n}) \omega(\mathrm{n}) \mathrm{V}_{\mathrm{d}}(\mathrm{n}) \mathrm{V}_{\mathrm{q}}(\mathrm{n}) \mathrm{C}_{\mathrm{em}}(\mathrm{n}) \omega(\mathrm{n}) \mathrm{i}_{\mathrm{q}}(\mathrm{n}) \omega(\mathrm{n}) \mathrm{i}_{\mathrm{d}}(\mathrm{n}) \omega(\mathrm{n})^{2}
\end{array}\right]^{\mathrm{T}}
\end{aligned}
$$




$$
P_{p}=\left(\begin{array}{lllllllll}
a_{11} & a_{12} & a_{13} & b_{11} & b_{12} & b_{13} & c_{11} & c_{12} & c_{13} \\
a_{21} & a_{22} & a_{23} & b_{21} & b_{22} & c_{23} & c_{21} & c_{22} & c_{23} \\
a_{31} & a_{32} & a_{33} & b_{31} & b_{32} & c_{33} & c_{31} & c_{32} & c_{33}
\end{array}\right)
$$

$P_{p}$ is the unknown matrix and defined as a parameter matrix, which includes the electrical and mechanical parameters of the motor. The vectors $Y_{p}$ et $Z_{p}$ are known. Where $Z_{p}$ is the regressor, and $Y_{p}$ is the measurement vector.

b) Motor parameters estimation

In order to determine the electrical and mechanical parameters, the intermediate parameters are formulated from parameter matrix $P_{p}$ as defined in paragraph above. Hence, we obtain the following equations:

$$
\begin{array}{ll}
\mathrm{a}=\mathrm{a}_{11}+\mathrm{a}_{22}=2-\frac{\mathrm{R}\left(\mathrm{L}_{\mathrm{d}}+\mathrm{L}_{\mathrm{q}}\right)}{\mathrm{L}_{\mathrm{d}} \mathrm{L}_{\mathrm{q}}} \Delta \mathrm{T} & \mathrm{f}=\mathrm{a}_{33}=1-\frac{\mathrm{f}_{\mathrm{v}} \Delta \mathrm{T}}{\mathrm{J}} \\
\mathrm{b}=\mathrm{b}_{11}+\mathrm{b}_{22}=\frac{\mathrm{L}_{\mathrm{d}}+\mathrm{L}_{\mathrm{q}}}{\mathrm{L}_{\mathrm{d}} \mathrm{L}_{\mathrm{q}}} \Delta \mathrm{T} & \mathrm{g}=\mathrm{b}_{33}=\frac{\Delta \mathrm{T}}{\mathrm{J}} \\
\mathrm{c}=\mathrm{a}_{22}-\mathrm{a}_{11}=-\frac{\mathrm{R}\left(\mathrm{L}_{\mathrm{d}}-\mathrm{L}_{\mathrm{q}}\right)}{\mathrm{L}_{\mathrm{d}} \mathrm{L}_{\mathrm{q}}} \Delta \mathrm{T} & \mathrm{e}=\mathrm{a}_{23}=\frac{\mathrm{p} \Phi_{\mathrm{m}}}{\mathrm{L}_{\mathrm{q}}} \Delta \mathrm{T} \\
\mathrm{d}=\mathrm{c}_{11}-\mathrm{c}_{22}=\mathrm{p}\left(\frac{\mathrm{L}_{\mathrm{d}}^{2}+\mathrm{L}_{\mathrm{q}}{ }^{2}}{\mathrm{~L}_{\mathrm{d}} \mathrm{L}_{\mathrm{q}}}\right) \Delta \mathrm{T} &
\end{array}
$$

Using these intermediate variables: $\mathrm{a}, \mathrm{b}, \mathrm{c}, \mathrm{d}, \mathrm{e}, \mathrm{f}$, and $\mathrm{g}$, the electrical and mechanical parameters of the motor are deduced as presented as follows:

$$
\begin{aligned}
& \widehat{\mathrm{R}}=\frac{2-\mathrm{a}}{\mathrm{b}} \\
& \widehat{\mathrm{L}_{\mathrm{d}}}=\frac{2(2-\mathrm{a})}{\mathrm{b}(2-\mathrm{a}-\mathrm{c})} \Delta \mathrm{T} \\
& \widehat{\mathrm{L}_{\mathrm{q}}}=\frac{2(2-\mathrm{a})}{\mathrm{b}(2-\mathrm{a}+\mathrm{c})} \Delta \mathrm{T} \\
& \widehat{\Phi_{\mathrm{m}}}=\frac{1}{\mathrm{p}} \frac{2 \mathrm{e}(2-\mathrm{a})}{\mathrm{b}(2-\mathrm{a}+\mathrm{c})} \\
& \widehat{\mathrm{J}}=\frac{\Delta \mathrm{T}}{\mathrm{g}} \\
& \widehat{\mathrm{f}_{\mathrm{v}}}=\frac{1-\mathrm{f}}{\mathrm{g}}
\end{aligned}
$$

\section{RESULT AND INTERPRETATION}

\subsection{Physical approach result}

\subsubsection{Experimental setup}

For the estimation of the BLDCM parameters, an experimental setup is described as presented in Figure 3. This protocol is made up of several equipment listed below:

- The brushless DC motor wheel + its controller;

- A DC generator to supply the motor;

- A signal or function generator to supply the motor phases;

- An oscilloscope to measure voltage;

- A multimeter to measure the resistance / voltage between phases;

- A current sensor to measure current;

- A rotary encoder to measure angular velocity; 
- An acquisition board that allows collecting the data received from sensors for its manipulation [30];

- A computer that enables the visualization of data;

- Weights that allow changing the resistive torque applied to the wheel;

The diagram above shows the experimental protocol to estimate the electrical and mechanical parameters of the motor.

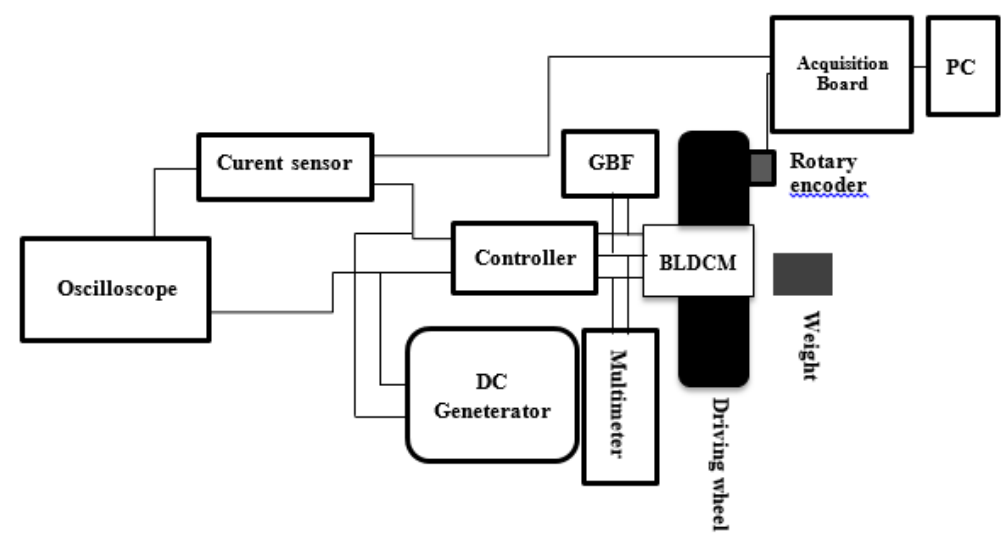

Figure 2. Experimental setup to estimate BLDC motor parameters

\subsubsection{Result of parametric estimation}

For this motor and while applying the method mentioned in the section 2, the coupling is star-connected because the ratio $a$ is about: $a=\frac{R_{2}}{R_{1}}=\frac{0.75}{1}=0.75$. Hence, the value of the stator resistance is $R=\frac{R_{1}}{2}=0.5 \Omega$. From the (4), we obtain the expression of the inductance $\mathrm{L}$ as shown as follows :

$$
\mathrm{L}=\frac{\sqrt{\mathrm{V}^{2}-4(\mathrm{iR})^{2}}}{2 \mathrm{i} \omega}
$$

Hence, the value of the inductance $\mathrm{L}$ is about $L=0.68 \mathrm{mH}$. To find the maximum magnetic flux $\phi_{m}$ according to the result obtained in experimental setup configured in Figure 3, the following characteristic $(\omega / \mathrm{i}, \mathrm{V} / \mathrm{i})$ is generated as shown in Figure 4.

This characteristic is fitting by a tendency line to estimate $p \phi_{m}$. Thus, while the (5) is compared to the regression line $(V / i=0,0502 \omega / i+0,7056)$, we get $\phi_{m}=\frac{5.0210^{-2}}{\mathrm{p}}$, Then $\phi_{m}=5.0210^{-2} \mathrm{~Wb}(\mathrm{p}=4$ in the case of our BLDC motor). The same procedure as $\phi_{m}$, and according to the experimental setup configured in Figure 3, the following characteristic $\left(\omega, y 1=p \phi_{m} i\right)$ is obtained in Figure 5. This characteristic is interpolated by a tendency line $\left(\mathrm{y} 1=1.610^{-3} \omega+0,0005\right)$ and compared to the (6). Hence, the value of the friction coefficient $f_{v}$ is about $f_{v}=1.610^{-3} \mathrm{Nmrad}^{-1} \mathrm{~s}^{-1}$.

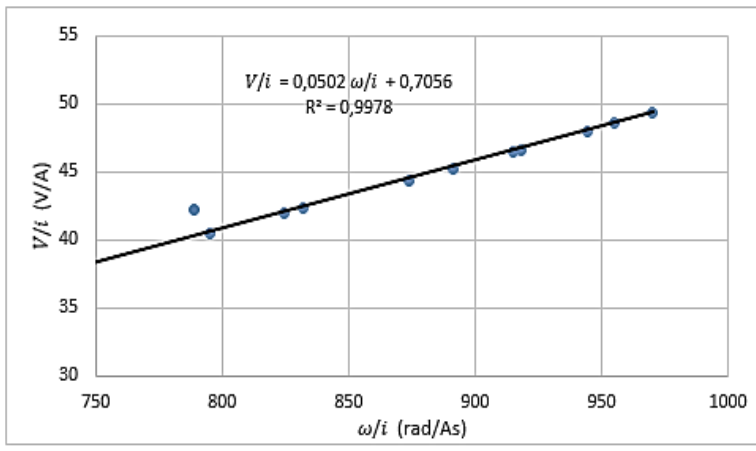

Figure 4. ( $\omega / \mathrm{i}, \mathrm{V} / \mathrm{i})$ characteristic obtained during the experimental setup

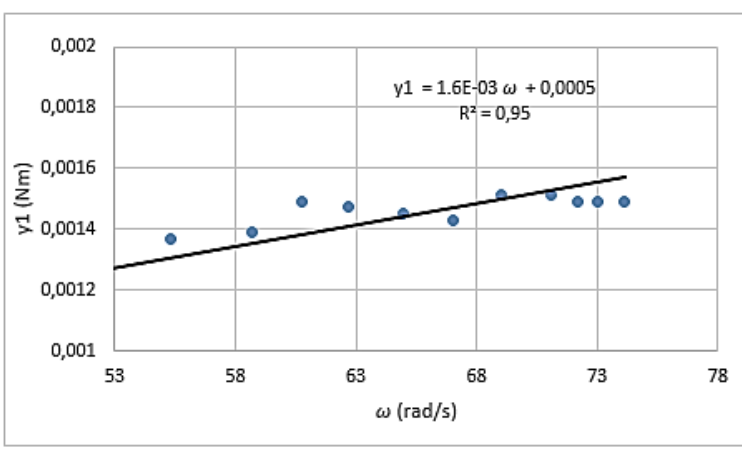

Figure 5. $\left.\left(\omega, \mathrm{y} 1=p \phi_{m} i\right)\right)$ characteristic obtained during the experimental setup 
To find the value of $\mathrm{J}$, the measurement is done during the coasting phase (because the duration of the transition phase is very short). And when several resistive torques are applied (several weights to the 8-inch wheel), according to the measurements obtained from the experimental setup see in Figure 3, the angular velocity of the wheel is quickly decreased while increasing the resistive torque. Hence, we obtain the angular accelerations during $1 \mathrm{~s}$ as defined in Table 1 as follows:

Table 1. Angular velocity with different resistive torque applied to the wheel

\begin{tabular}{cccc}
\hline Weight $(\mathrm{g})$ & Torque $(\mathrm{Nm})$ & Angular velocity $\boldsymbol{\omega}(\mathrm{rad} / \mathrm{s})$ at Time $=1 \mathrm{~s}$ & Angular deceleration $\frac{d \boldsymbol{\omega}}{d t}\left(\mathrm{rad} / \mathrm{s}^{2}\right)$ \\
\hline 0 & 0 & 30 & -0.5 \\
$100 \mathrm{~g}$ & 0.2 & 18 & -0.7 \\
$200 \mathrm{~g}$ & 0.4 & 10 & -1 \\
$300 \mathrm{~g}$ & 0.6 & 4 & -1.1 \\
\hline
\end{tabular}

Hence the characteristic $\left(\frac{d \omega}{d t}, \mathrm{y} 2=f_{v} \omega\right)$ is given as follows in the Figure 6 . This characteristic is fitted by a regression line to estimate $\mathrm{J}$, by identifying (7) with the tendency line (y2 $=0,0644 d \omega / d t+$ $0,0779)$, we obtain $J=0.0644 \mathrm{Kgm}^{2}$. The physical approach is particularly accurate for the estimation of the electrical and mechanical parameters of the motor, it shows compatible with the value given at the bibliography. Hence, these values are used to estimate all parameters using weighted recursive least square algorithm.

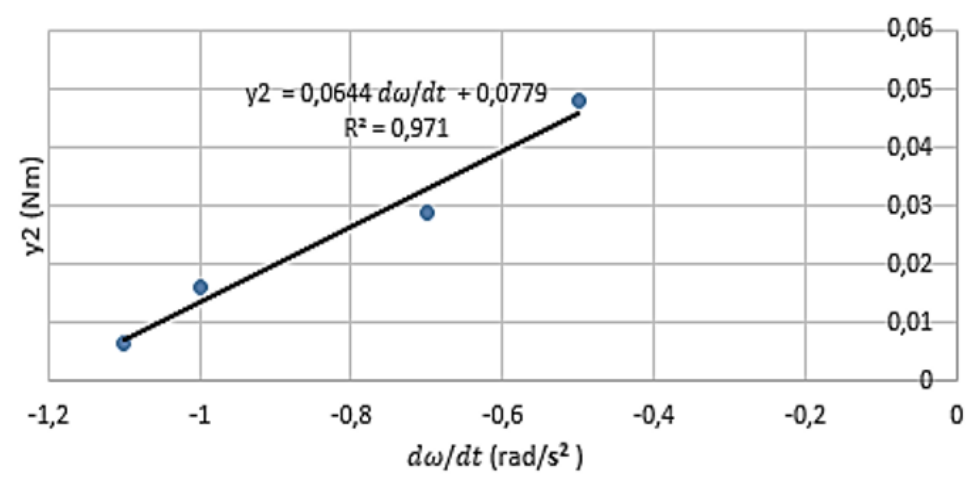

Figure 3. $\left(\frac{d \omega}{d t}, y 2\right)$ characteristic obtained during the experimental setup

\subsection{Online estimation approach}

\subsubsection{Preliminary process}

In this section, we apply identification technique to the motor modeling while controlling the current and the angular velocity using Park's reference frame in order to simplify regulation as found in [31-34]. The real values of these parameters are taken from the physical approach found previously. Simulation and control modeling are done using the Matlab Simulink software presented in Figure 2. The identification is performed both on-line and in closed loop to maintain the stability of the motor's behavior, as well as its dynamics in transient states. The identification method used to identify parameters is known as the input error method and illustrated in the schematic diagram as shown in Figure 7.

As the inverter generates noise during running, it is important to filter the measured data before the identification process. The role of pre-filtering is two-fold: The first one is to estimate the parameters of the regression matrix within the frequency bandwidth of interest, and the second one is to decrease the variance of the estimator. Therefore, a non-causal low-pass filter type Butterworth was chosen for filtering the measured inputs and outputs. Furthermore, in order to keep information on the system dynamics, we take the cutoff pulsation of this filter such as $\omega_{c f e}=4 \omega_{c c}$ et $\omega_{c f m}=4 \omega_{c v}$. Where these parameters are defined as follows:

- $\omega_{c f e}$ is the cutoff pulsation of the filter related to the electrical measurements,

- $\omega_{c f m}$ is the cutoff pulsation of the filter related to the mechanical measurements, 
- $\omega_{c c}$ is the pulsation of the current controller,

- $\omega_{c v}$ is the pulsation of the angular velocity controller.

Then the measured $i_{d}, i_{q}, V_{d}, C_{e m}, \omega$ and $V_{q}$, are obtained from these filtered data.

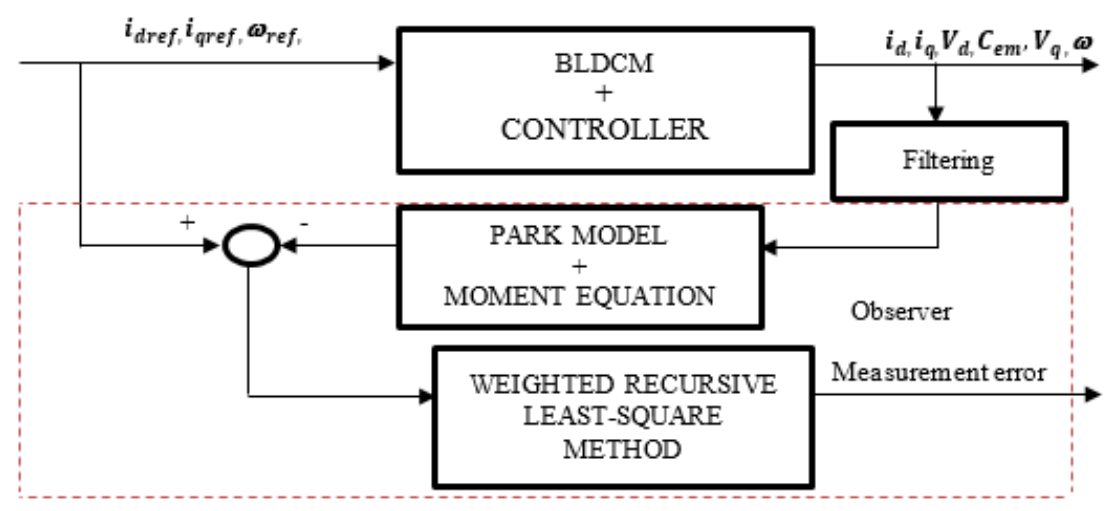

Figure 4. Parametric identification based on input error

\subsubsection{Result of approach}

To identify the parameter matrix $P_{p}$ given in (12) (the index p denotes the electrical and mechanical parameters), a weighted recursive least square algorithm is used [35-38]. $\lambda$ is defined as the forgetting factor, whose role is to delete past data.

- start-up:

- Let's wait until we have enough data to make $\mathrm{R}(\mathrm{n}=\mathrm{M})$ reversible. and set with:

$$
\left\{\begin{array}{c}
P(M)=R^{-1}(M) \\
P_{p}(M) \\
=P(M) V(M)
\end{array}\right\}
$$

- Initialize with :

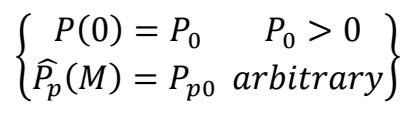

- Calculate the correction gain:

$$
K(n+1)=\frac{P(n) Z}{\lambda+Z^{T} \mathrm{P}(\mathrm{n}) \mathrm{Z}}
$$

- Update P:

$$
P(n+1)=\frac{1}{\lambda}\left(P(n)-K(n+1) Z^{T} P(n)\right)
$$

- Output Prediction:

$$
\hat{Y}(n+1)=Z^{T} \widehat{P_{p}(n)}
$$

- Updating parameters:

$$
P_{p}(\widehat{n+1})=\widehat{P_{p}(n)}+K(n+1)(Y(n+1)-\hat{Y}(n+1))
$$

- Deduce the electrical and mechanical parameters with the help of the intermediate variables obtained from the components of the parameter's matrix $P_{p}$ using the (13), (14), (15), (16), (17) and (18).

Simulation under Simulink gives us;

Motor parameters are described in Table 2 as follows: 
Table 2. Motor parameters estimation using recursive least square algorithm

\begin{tabular}{cccccc}
\hline $\mathrm{R}$ & $\mathrm{L}_{\mathrm{d}}$ & $\mathrm{L}_{\mathrm{q}}$ & $\phi_{\mathrm{m}}$ & $\mathrm{J}$ & $\mathrm{f}_{\mathrm{v}}$ \\
\hline 0.45 & 0.6981 & 0.70 & 1.3 & 1.069 & 1.79 \\
\hline
\end{tabular}

The results of the sensorless estimation of the direct current, quadratic currents and angular velocity are shown in Figures 8, 9 and 10. In this paper we give a sampling period $\Delta \mathrm{T}=210^{-3} \mathrm{~s}$ and $\lambda=0.99$. We notice that both the current and angular velocity measured and estimated curves converge producing a small error as shown in the Figures 11-13.

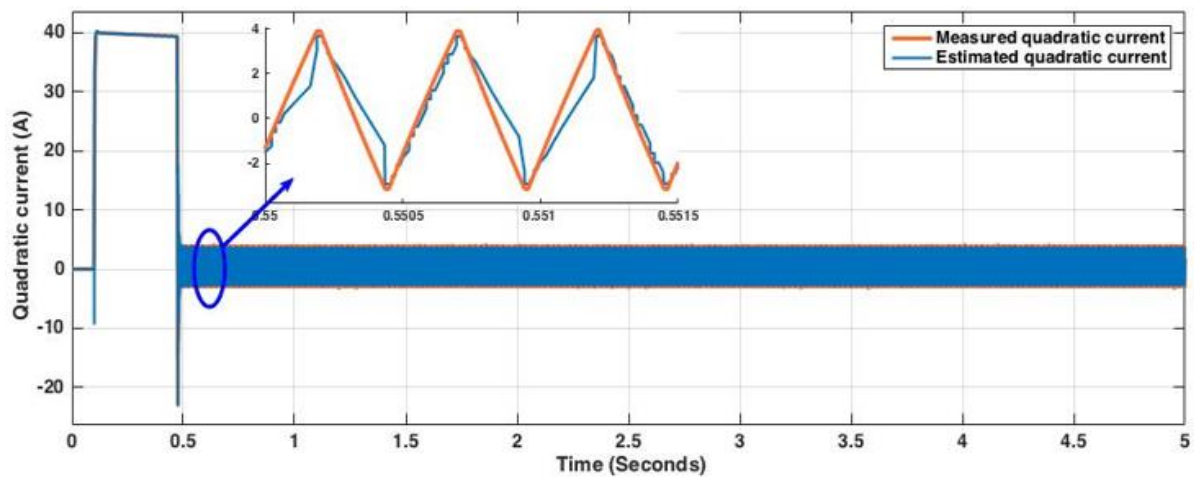

Figure 5. Quadratic current measured and estimated as a function of time

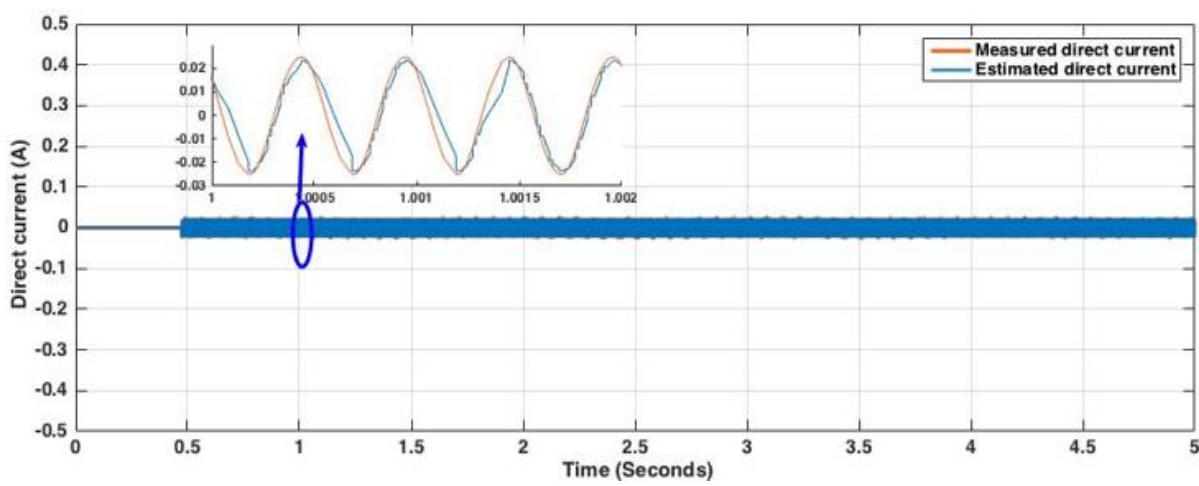

Figure 6. Direct current measured and estimated as a function of time

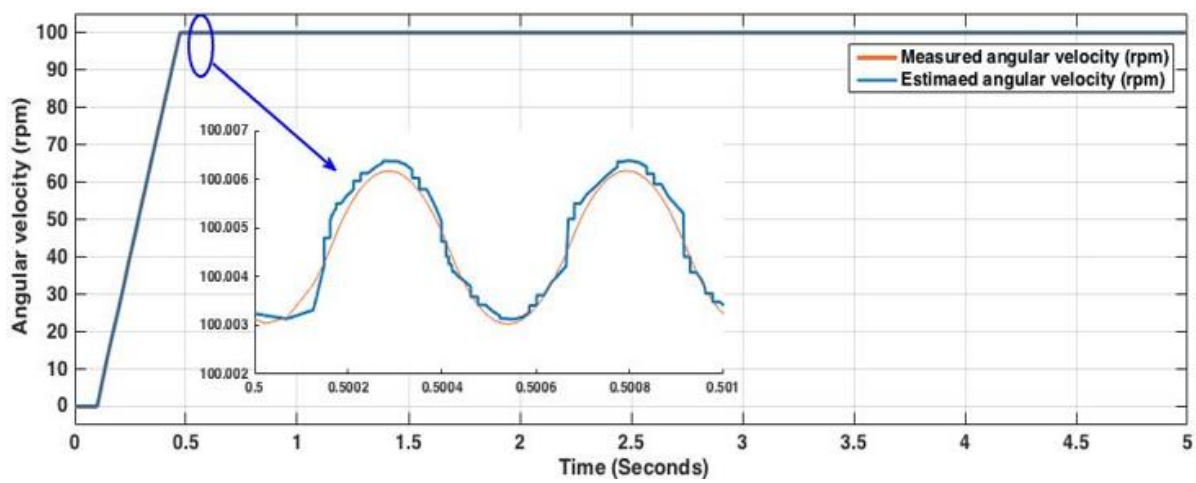

Figure 10. Angular velocity measured and estimated as a function of time 


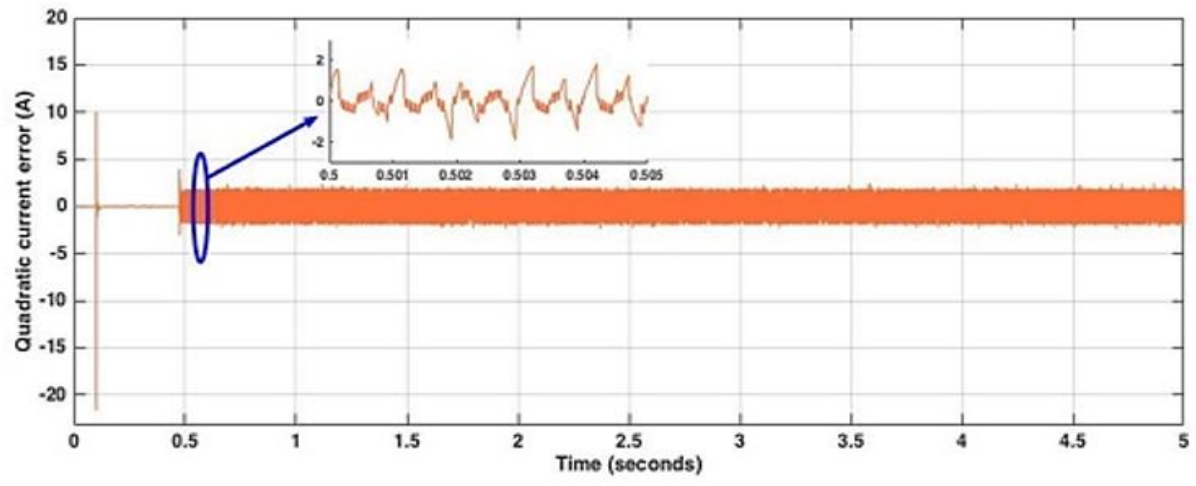

Figure 11. Quadratic current error as a function of time

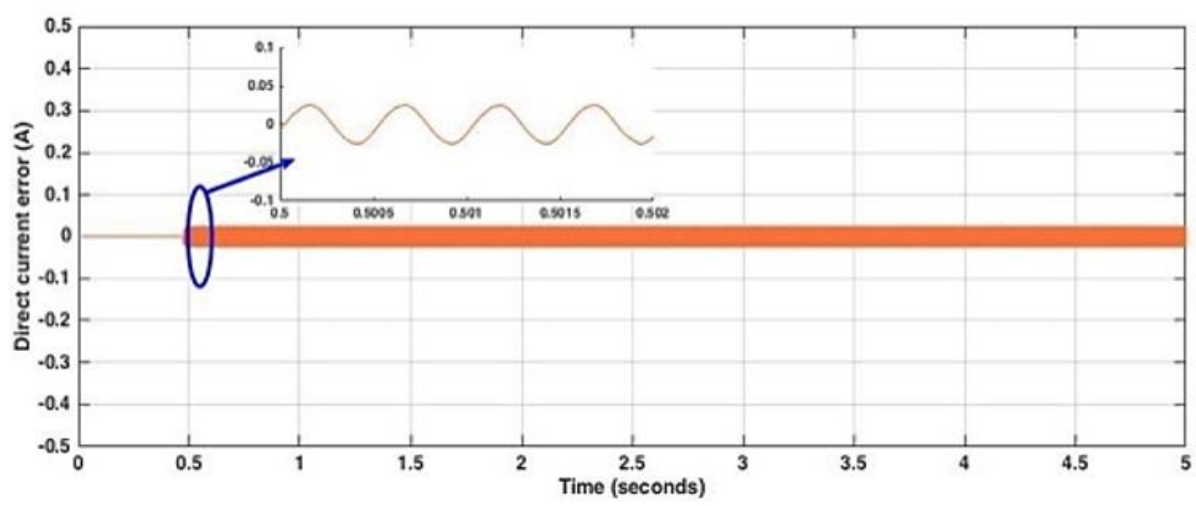

Figure 12. Direct current error as a function of time

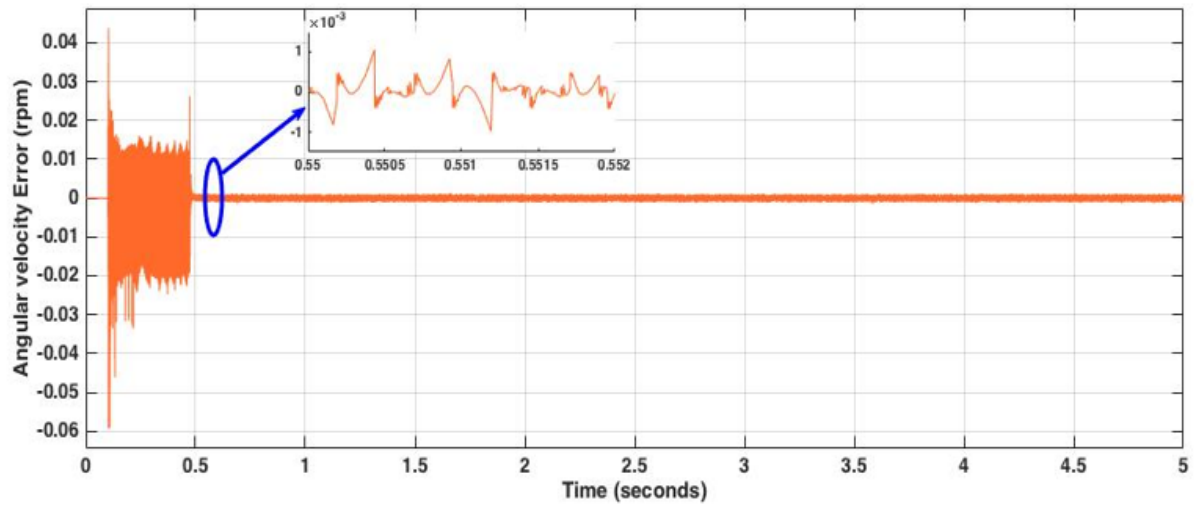

Figure 7. Angular velocity error as a function of time

The relative error of the estimation of these parameters is calculated using (19) [39].

$$
\text { Error }=100\left|\frac{\text { Physical approach value-Estimated value }}{\text { Physical approach value }}\right|
$$

The Table 3, shows the result of parameter estimation using physical approach based on experimentation, and the online estimation approach based on weighted recursive least square algorithm. These parameters are evaluated using relative error as mensioned in (19). By using relative error, the results of weighted recursive least square method give us electrical and mechanical parameters around the parameters obtained in physical approach established previously. 
Table 3. Physical approach parameters, estimation approach parameters and measuring error

\begin{tabular}{ccccccc}
\hline Parameters & $\mathrm{R}$ & $\mathrm{L}_{\mathrm{d}}$ & $\mathrm{L}_{\mathrm{q}}$ & $\phi_{\mathrm{m}}$ & $\mathrm{J}$ & $\mathrm{f}_{\mathrm{v}}$ \\
\hline Physical approach values & 0.5 & 0.68 & 0.68 & 1.255 & 1.0644 & 1.6 \\
Estimated values & 0.45 & 0.6981 & 0.70 & 1.3 & 1.069 & 1.79 \\
Relative Error & $10 \%$ & $2.66 \%$ & $2.94 \%$ & $3.58 \%$ & $7.14 \%$ & $11.87 \%$ \\
\hline
\end{tabular}

\section{CONCLUSION}

In this paper, two different procedures for parameter identification and estimation have been proposed to provide a reliable model of a BLDCM. The first one is performed by applying the physical approach, and it uses available data provided by experimentation. The second one is an online estimation method based on the weighted recursive least square algorithm method, implemented on a closed loop control scheme to maintain the stability of the system. The obtained results for both procedures are very satisfying, and the error between these parameters values obtained from physical approach, conducted in continuous time, and the estimation approach, conducted in discrete time, are negligible. The detailed procedures also provide a precise estimation of the angular velocity and the electromagnetic torque generated by the motor, thus it's very useful to various sensorless BLDCM control schemes that will be explored in coming studies.

\section{ACKNOWLEDGEMENTS}

The authors of this paper are thankful to the Ministry of Higher Education and Scientific Research of Morocco (MESRSFC), and the National Center for Scientific and Technical Research of Morocco (CNRST) for financing this project.

\section{REFERENCES}

[1] J. Baillieul, "Encyclopedia of Systems and Control," Springer Publishing Company, Incorporated, 2020.

[2] H. Garnier, M. Gilson, and T. Bastogne, "Identification de modèles paramétriques à temps continu. Méthodes, outil logiciel et avantages-Identification of continuous time parametric models. Methods, software tool and advantages (in French)," hal.archives-ouvertes.fr, 2006.

[3] C. Sovardi, S. Jaensch, K. Forner, Selimefendigil, F., and W. Polifke, "Parametric vs. Nonparametric Identification of Nonlinear Acoustic Scattering at Duct Discontinuities based on LES data," Proceedings of the Summer Program, pp. 1-8, 2013.

[4] I. Z. Mat Darus and M. O. Tokhi, "Parametric and non-parametric identification of a two dimensional flexible structure," Journal of low frequency noise, vibration and active control, vol. 25, no. 2, pp. 119-143, 2006.

[5] M. G. Bekker, "Introduction to terrain-vehicle systems," Michigan Univ Ann Arbor, 1969.

[6] C. L. Xia, "Permanent Magnet Brushless DC Motor Drives and Controls," John Wiley \& Sons, 2012.

[7] L. Ljung, "System Identification," Wiley encyclopedia of electrical and electronics engineering, pp. 1-9, 1999.

[8] N. T. García, Y. A. G. Gómez, and F. E. H. Velasco, "Parameter estimation of three-phase linear induction motor by a DSP-based electric-drives system," International Journal of Electrical and Computer Engineering (IJECE), vol. 10, no. 1, pp. 626-636, 2020.

[9] Y. Bar-Shalom, X.-R. Li, and T. Kirubarajan, "Estimation with Applications to Tracking and Navigation," John Wiley \& Sons, vol. 9, 2001.

[10] Q. Wang, S. Wang, and C. Chen, "Review of sensorless control techniques for PMSM drives," IEEJ Transactions on Electrical and Electronic Engineering, vol. 14, no. 10, pp. 1543-1552, 2019.

[11] P. P. Acarnley and J. F. Watson, "Review of position-sensorless operation of brushless permanent-magnet machines," IEEE Transactions on Industrial Electronics, vol. 53, no. 2. pp. 352-362, 2006.

[12] S. S. Alex and A. E. Daniel, "Optimal Gain Selection Strategy in Back EMF Observer for Position Sensorless Operation of BLDC Motors," Arabian Journal for Science and Engineering, 2019.

[13] G. Mamani, J. Becedas, V. Feliu-Batlle, and H. Sira-Ramirez, "Open-loop algebraic identification method for a DC motor," European Control Conference (ECC), pp. 3430-3436, 2007.

[14] J. Becedas, G. Mamani, and V. Feliu, "Algebraic parameters identification of DC motors: Methodology and analysis," International journal of systems science, vol. 41, no. 10, pp. 1241-1255, 2010.

[15] R. Krneta, S. Antic, and D. Stojanovic, "Recursive least squares method in parameters identification of DC motors models," Facta universitatis-series: Electronics and Energetics, vol. 18, no. 3, pp. 467-478, 2005.

[16] Y. Mohamed, B. Hasaneen, A. Elbaset, and A. Hussein, "Recursive Least Square Algorithm for Estimating Parameters of an Induction Motor," Journal of Engineering Sciences, Assiut University, vol. 39, no. 1, pp. 87-98, 2011.

[17] R. Sarić, D. Jokić, E. Čustović, and Ž. Jurić, "Experimental Parametric Identification in Closed-Loop Feedback using Novel Approach to the Linear Control Systems," IFAC-PapersOnLine, vol. 52, no. 27, pp. 13-18, 2019.

[18] H. P. Nee, "Determination of d and q reactances of permanent-magnet synchronous motors without measurements of the rotor position," IEEE Transactions on Industry Applications, vol. 36, no. 5, pp. 1330-1335, 2000. 
[19] S. Bolognani and K. Unterkofler, "On-line Parameter Commissioning in Sensorless PMSM Drives.," IEEE Int. Symp. Ind. Electron., vol. 2, pp. 480-484, 2000.

[20] A. Soldatov, S. Gladkich, "Religion und Staat: Die Russische Orthodoxe Kirche und der geistliche Raum Rußlands - Religion and State: The Russian Orthodox Church and the Spiritual Area of Russia (in German)," Osteuropa, pp. 74-81, 2004.

[21] A. Andreev, M. Andreev, D. Kolesnihenko, R. R. Dyganova, G. T. Merzadinova, and I. K. Ibraev, "Parametric identification algorithm for asynchronous electric motor inverter on the switching intervals of power transistors," E3S Web Conf., vol. 124, pp. 4-8, 2019.

[22] M. Frolov, I. Dulov, and I. Yunusova, "Identification of asynchronous motor parameters in operational mode," Proc. - 2019 Int. Ural Conf. Electr. Power Eng. Ural., pp. 86-91, 2019.

[23] K. Rutczyńska-Wdowiak, "The generating new individuals of the population in the parametric identification of the induction motor problem with the use of the genetic algorithm," Czas. Tech., no. 2, pp. 109-118, 2019.

[24] Rania Majdoubi, Lhoussaine Masmoudi, "Etude et conception d'un robot mobile écologique dédié à la pulvérisation des fraises sous serre - Study and design of an ecological mobile robot dedicated to spraying strawberries in greenhouses (in French)," Journées d'Etudes Techniques 2018 de l'Association Franco-Maghrebine de Mécanique et des Matériaux (AF3M), 2018.

[25] Rania Majdoubi, Lhoussaine Masmoudi, "Study And Design of An Ecological Mobile Robot For Spraying Strawberries in Greenhouses," The International Conference on Micro and NanoSatellites., 2018.

[26] V. S. Veena and J. E. College, "Motor Drive for Aerospace Application," Int. Conf. Magn. Mach. Drives (AICERA2014 iCMMD), pp. 1-5, 2014.

[27] M. Kumar, B. Singh, and B. P. Singh, "Modeling and Simulation of Permanent Magnet Brushless Motor Drives using Simulink," Natl. power Syst. Conf. NPSC, no. 5, pp. 253-258, 2002.

[28] N. Cherfia and D. Kerdoun, "Wind Energy Conversion Systems Based On a DFIG Controlled By Indirect Vector Using PWM And SVM," International Journal of Electrical and Computer Engineering (IJECE), vol. 6, no. 2, pp. 549-559, 2016.

[29] R. Errouissi, "Contribution à la commande prédictive non linéaire d'une machine synchrone à aimants permanents," Contrib. à la Command. prédictive non linéaire d'une Mach. synchrone à aimants Perm., 2010.

[30] S. Achouch, L. Masmoudi, M. Gharbi, and P. Nonnon, "Design and development of a sensor for distance and velocity measurement using an Infrared camera for studying kinematic movements," Int. Conf. Wirel. Technol. Embed. Intell. Syst., pp. 1-6, 2019.

[31] S. B. Ozturk and H. A. Toliyat, "Direct torque and indirect flux control of brushless DC motor," IEEE/ASME Trans. Mechatronics, vol. 16, no. 2, pp. 351-360, 2011.

[32] R.EAnuradha, M. Anbuselvi, and P.Saravanan, "Torque ripple minimisation of bldc motor using vector control algorithm," Int. J. Emerg. Technol. Comput. Sci. Electron., vol. 23, no. 2, pp. 94-97, 2016.

[33] N. A. Yusoff, A. M. Razali, K. A. Karim, R. Nor, F. Kashfi, and R. Othman, "Analysis of direct power control ACDC converter under unbalance voltage supply for steady-state and dynamic response," International Journal of Electrical and Computer Engineering (IJECE), vol. 10, no. 4, pp. 3333-3342, 2020.

[34] M. Lazor and M. Stulrajter, "Modified field oriented control for smooth torque operation of a BLDC motor," Proceedings 10th International Conference, ELEKTRO - pp. 180-185, 2014.

[35] W. Shan, L. Li, W. Zhao, and Q. He, "Research on weighted least square optimization algorithm of nonlinear system analysis," International Conference on Mechatronics, Control and Electronic Engineering, pp. 231-234, 2014.

[36] B. Kovačević, Z. Banjac, and I. K. Kovačević, "Robust adaptive filtering using recursive weighted least squares with combined scale and variable forgetting factors," EURASIP J. Adv. Signal Process., vol. 2016, no. 1, 2016.

[37] Y. Naderahmadian, M. A. Tinati, and S. Beheshti, "Generalized adaptive weighted recursive least squares dictionary learning," Signal Processing, vol. 118, pp. 89-96, 2016.

[38] L. Ljung and 1999 River, NJ: Prentice-Hall, "System Identification-Theory for the User. Upper Saddle," Up. Saddle River, NJ Prentice-Hall, pp. 1689-1699, 1999.

[39] C. J. Wenning, “Absolute and Relative Error,” Student Lab. Handb., 2014. 